\title{
Anticorrosive Performance of Zinc Phosphate Coatings on Mild Steel Developed Using Galvanic Coupling
}

\author{
M. Arthanareeswari, ${ }^{1}$ P. Kamaraj, ${ }^{1}$ and M. Tamilselvi ${ }^{2}$ \\ ${ }^{1}$ Department of Chemistry, Faculty of Engineering and Technology, SRM University, Chennai 603203, India \\ ${ }^{2}$ Department of Chemistry, Thiru Kolanjiappar Government Arts College, Virudhachalam 606001, India \\ Correspondence should be addressed to M. Arthanareeswari; arthanareeswari@gmail.com
}

Received 10 June 2012; Accepted 27 September 2012

Academic Editor: Rafael Garcia-Tenorio

Copyright (c) 2013 M. Arthanareeswari et al. This is an open access article distributed under the Creative Commons Attribution License, which permits unrestricted use, distribution, and reproduction in any medium, provided the original work is properly cited.

\begin{abstract}
The anticorrosive performance of zinc phosphate coatings developed by galvanic coupling technique on mild steel substrates using the cathode materials such as titanium (Ti), copper (Cu), brass (BR), nickel (Ni), and stainless steel (SS) is elucidated in this study. Thermal and chemical stability tests, immersion test in 3.5\% NaCl, ARE salt droplet test, and salt spray test were carried out. The study reveals that the mild steel substrates phosphated under galvanically coupled condition showed better corrosion resistance than the one coated without coupling. The open circuit potential (OCP) of phosphated mild steel panels in $3.5 \% \mathrm{NaCl}$ was found to be a function of phosphate coating weight and porosity of the coating.
\end{abstract}

\section{Introduction}

Phosphating is the most widely used metal pretreatment process for the surface treatment and finishing of ferrous and nonferrous metals. Due to its economy, speed of operation and ability to afford excellent corrosion resistance, wear resistance, adhesion, and lubricative properties, it plays a significant role in the automobile, process and appliance industries [1-4]. Though known to be in use since the 1940s $[5,6]$, the low temperature phosphating processes have become more significant today due to the escalating energy costs. However, low temperature phosphating processes are very slow and need to be accelerated by some means. Acceleration of the phosphating process could be achieved by chemical, mechanical, and electrochemical methods. However, each of them has some limitations and/or detrimental effects. Chemical accelerators are the preferred choice in many instances. The use of nitrites as the accelerator is the most common in low temperature-operated phosphating baths. However, a higher concentration of nitrite is required to increase the rate of deposition of phosphate coatings at low temperatures. The environmental protection agency (EPA) has classified nitrite as toxic in nature, and hence use of nitrite as accelerator could cause disposal problems [7]. The utility of the galvanic coupling for accelerating low temperature zinc phosphating processes was established recently [8-12].

The present work aims to study the thermal and chemical stabilities of panels phosphated under coupled and uncoupled conditions and their performance in $3.5 \% \mathrm{NaCl}$ test, ARE salt droplet test, and salt spray test.

\section{Experimental Details}

Mild steel specimens of dimensions $8.0 \mathrm{~cm} \times 6.0 \mathrm{~cm} \times 0.2 \mathrm{~cm}$ were used as the substrate materials for the deposition of zinc phosphate coating. Titanium, copper, brass, nickel, and stainless steel (AISI 304 grade) substrates were used to create the galvanic coupled with mild steel substrate with varying anodic to cathodic area ratio [8]. The schematic of the experimental setup used for the phosphating process was reported [8]. The chemical composition of the zinc phosphating bath and its operating conditions are given in Table 1.

The phosphate coatings were developed by galvanic coupling technique using various cathode materials such as titanium (Ti), copper $(\mathrm{Cu})$, brass $(\mathrm{BR})$, nickel $(\mathrm{Ni})$, and stainless steel (SS). The amount of iron dissolved during phosphating and coating weight was determined and reported [8]. 
TABLE 1: Chemical composition, control parameters, and operating conditions of the bath used for zinc phosphating by galvanic coupling.

\begin{tabular}{lcc}
\hline \multicolumn{3}{c}{ Chemical composition } \\
\hline $\mathrm{ZnO}$ & & $5 \mathrm{~g} / \mathrm{L}$ \\
$\mathrm{H}_{3} \mathrm{PO}_{4}$ & & $11.3 \mathrm{~mL} / \mathrm{L}$ \\
$\mathrm{NaNO}_{2}$ & $2 \mathrm{~g} / \mathrm{L}$ \\
\hline & Control parameters \\
\hline $\mathrm{pH}$ & & 2.70 \\
Free acid value (FA) & 3 pointage \\
Total acid value (TA) & & 25 pointage \\
FA: TA & Operating condition & $1: 8.33$ \\
\hline & & $27^{\circ} \mathrm{C}$ \\
\hline Temperature & & 30 minutes \\
Time & & \\
\hline
\end{tabular}

Same operating conditions and phosphating bath are used for phosphating the uncoupled mild steel for comparison.

Thermal stability was studied by subjecting the preweighed phosphated panels to thermal treatment at $120^{\circ} \mathrm{C}$ and $180^{\circ} \mathrm{C}$ for 30 minutes (simulated thermal aggression conditions). The percentage loss in weight obtained was related to the thermal stability of the phosphate coating [13-16]. Chemical stability was studied by determining the loss in weight obtained by immersion treatment (simulated conditions for cosmetic corrosion) of the phosphated panels at representative $\mathrm{pH}$ values $(\mathrm{pH} 3.05,4,7.05$, and 10) in the acidic, neutral, and alkaline conditions (simulated chemical aggression conditions), for a duration of 30 minutes. The percentage residual coating weight obtained was correlated with the chemical stability of the phosphate coatings $[13,14]$. Phosphated mild steel panels were immersed in 3.5\% sodium chloride solution, and the weight loss after 24 hours of immersion was also determined.

ARE salt droplet test was carried out using phosphated panels sprayed on both sides once daily for 5 days with a spray solution of the following composition: sodium chloride, $\mathrm{NaCl} 23.0 \mathrm{~g} / \mathrm{L}$, sodium sulphate $\mathrm{Na}_{2} \mathrm{SO}_{4} \cdot 10 \mathrm{H}_{2} \mathrm{O} 8.9 \mathrm{~g} / \mathrm{L}$, magnesium chloride $\mathrm{MgCl}_{2} \cdot 6 \mathrm{H}_{2} \mathrm{O} 9.8 \mathrm{~g} / \mathrm{L}$, calcium chloride (anhyd.), and $\mathrm{CaCl}_{2} 1.2 \mathrm{~g} / \mathrm{L}$.

Immediately after spraying, the specimens were suspended vertically in a closed chamber partially filled with water in such a way that the distance between the surface of water and the lower edge of the specimens were $5 \mathrm{~cm}$. The temperature inside the test chamber was maintained at $27^{\circ} \mathrm{C}$ using a constant temperature bath. At the end of the test period, the specimens were rusted in Clarke's solution (20 g of antimony trioxide and $50 \mathrm{~g}$ of stannous chloride dissolved in one litre of hydrochloric acid (Sp.gr 1.16)), washed in running water, dried, and weighed. The difference in weight between the freshly degreased specimen and the corresponding weight after derusting gave the average weight loss (IS: 3618-1966) $[15,16]$.

Salt spray test was carried out by subjecting the phosphated panels to a salt mist of $5 \%$ sodium chloride solution in a salt spray chamber (ASTM B 117-03) for a specified period of time (24 hours) [17]. The edges of the substrates were sealed with paraffin wax to avoid the excessive corrosion at the edges. The extent of corrosion after 24 hours of exposure was assessed and photographed.

\section{Results and Discussion}

The effect of galvanic coupling of mild steel substrate with titanium, copper, brass, nickel, and stainless steel substrates on the amount of iron dissolved during phosphating and coating weight was reported [8]. It was evident from the report that the extent of metal dissolution and coating formation is higher for mild steel substrates phosphated under galvanically coupled condition than the one coated without coupling [9]. It is understandable that galvanic coupling accelerates the initial metal dissolution reaction and enables an earlier attainment of the point of incipient precipitation (PIP), that is, the point at which saturation of metal dissolution occurs and higher coating weight results.

3.1. Thermal Stability. The percentage weight loss obtained for panels coated using galvanic coupling, subjected to $120^{\circ} \mathrm{C}$ and $180^{\circ} \mathrm{C}$ for 30 minutes, is given in Figures 1 (a)-1(e) along with the uncoupled specimens for effective comparison. The percentage loss in weight was found to be more for substrates coated under uncoupled condition than those coated under coupled conditions. Among the different couples studied, namely, mild steel-titanium, mild steel-copper, mild steelbrass, mild steel-nickel, and mild steel-stainless steel, the mild steel phosphated using titanium as cathode material has less percentage loss in weight compared to the other couples. The percentage loss in weight was found to be decreasing with increase in the coating weight of the substrates which in turn is due to the higher potential difference between the anode and cathode materials of the galvanic couple used for zinc phosphating.

3.2. Chemical Stability. The measure of the percentage residual coating weight obtained for galvanically coupled and uncoupled phosphated substrates from immersion tests at acidic, neutral, and alkaline ranges is given in Figures 2(a)2(e). The percentage residual coating weight was found to be more in the case of mild steel specimens phosphated using galvanic coupling with titanium, where the potential difference between the couple is greater. The percentage residual coating weight decreases in the following order of galvanic couple used for phosphating: (i.e.,) mild steeltitanium $>$ mild steel-copper $>$ mild steel-brass $>$ mild steelnickel $>$ mild steel-stainless steel.

The increase in the percentage loss in weight following thermal treatment at $120^{\circ} \mathrm{C}$ and $180^{\circ} \mathrm{C}$ is due to the loss of associated water molecules from the two phases of the zinc phosphate coating, namely, hopeite $\left[\mathrm{Zn}_{3}\left(\mathrm{PO}_{4}\right)_{2} \cdot 4 \mathrm{H}_{2} \mathrm{O}\right]$ and phosphophyllite $\left[\mathrm{Zn}_{2} \mathrm{Fe}\left(\mathrm{PO}_{4}\right)_{2} \cdot 4 \mathrm{H}_{2} \mathrm{O}\right]$. At $120^{\circ} \mathrm{C}$, hopeite looses two molecules of water, while at $180^{\circ} \mathrm{C}$, it looses the remaining two molecules; whereas in the case of phosphophyllite even at $180^{\circ} \mathrm{C}$, only two molecules of water of hydration are lost $[17,18]$. 


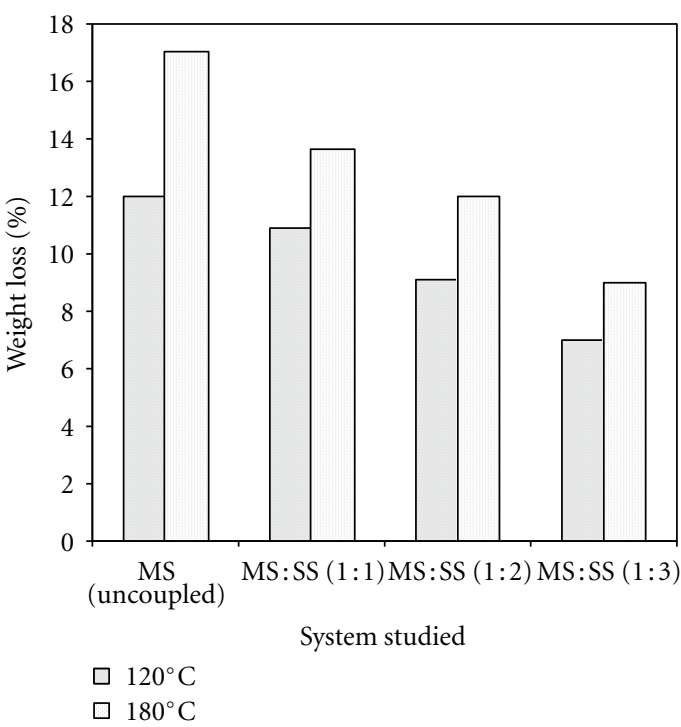

(a)

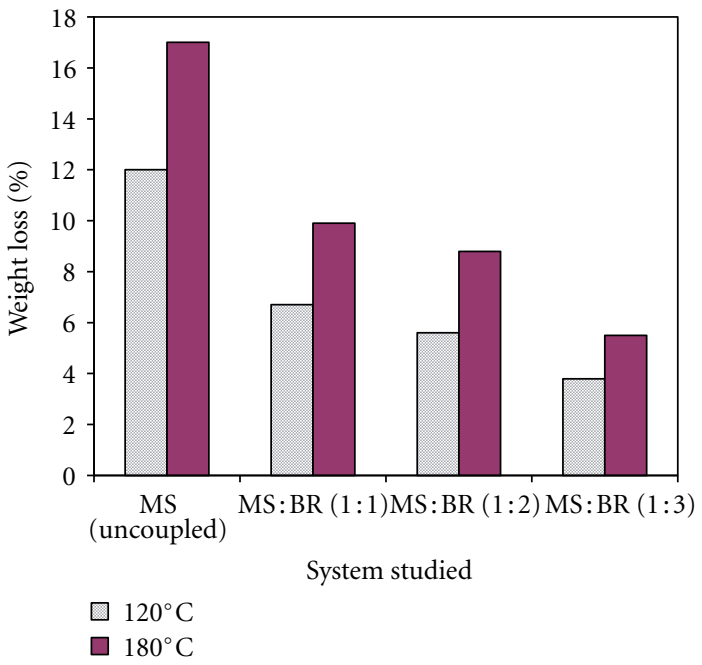

(c)

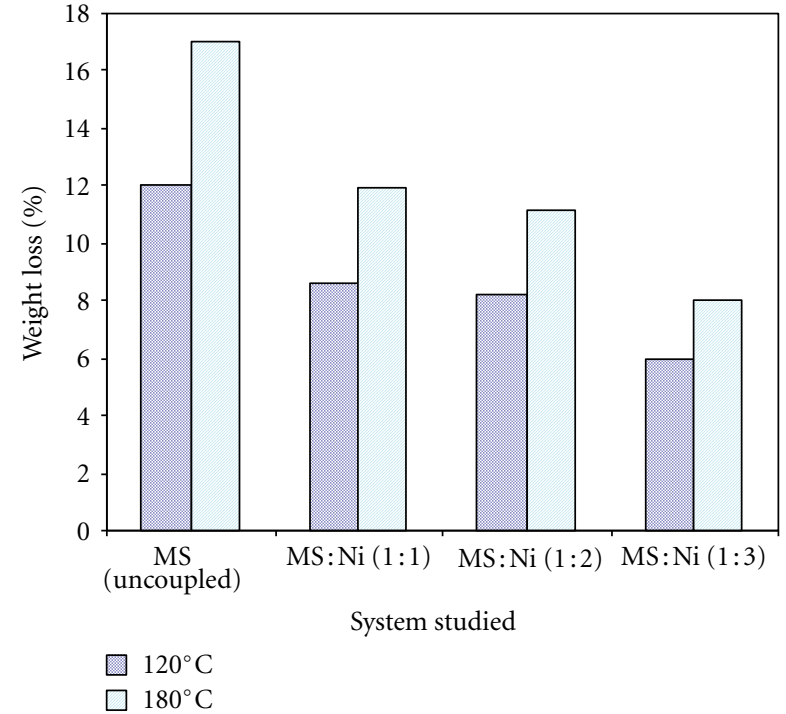

(b)

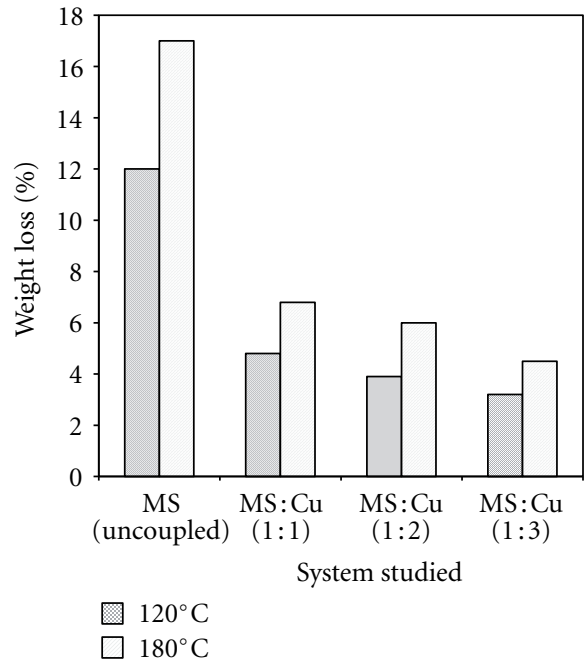

(d)

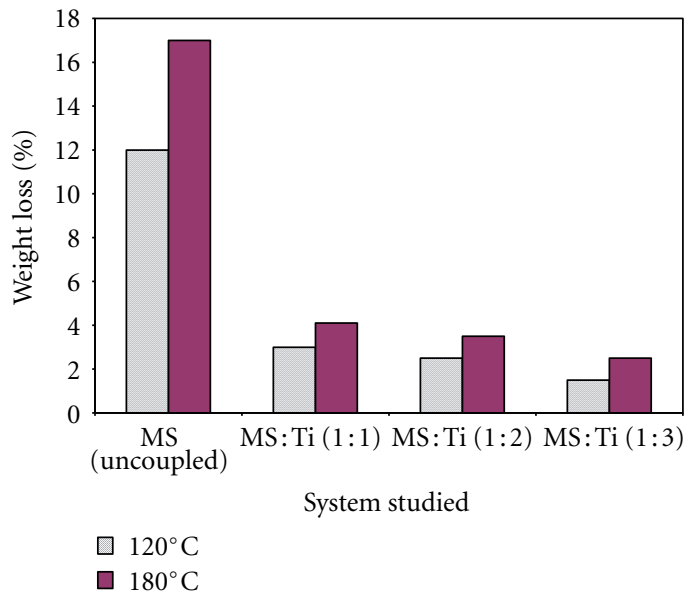

(e)

FIGURE 1: Thermal stability of phosphate coatings obtained under uncoupled and galvanically coupled conditions: (a) mild steel coupled with stainless steel (area ratio of MS to SS-1:1,1:2, and $1: 3$ ); (b) mild steel coupled with nickel (area ratio of MS to Ni-1:1,1:2, and $1: 3$ ); (c) mild steel coupled with brass (area ratio of MS to BR-1:1,1:2 and $1: 3$ ); (d) mild steel coupled with copper (area ratio of MS to Cu-1:1,1:2, and $1: 3$ ); (e) mild steel coupled with titanium (area ratio of MS to Ti-1:1,1:2, and $1: 3$ ) when subjected to thermal treatment at $120^{\circ} \mathrm{C}$, and $180^{\circ} \mathrm{C}$ for 30 minutes. 


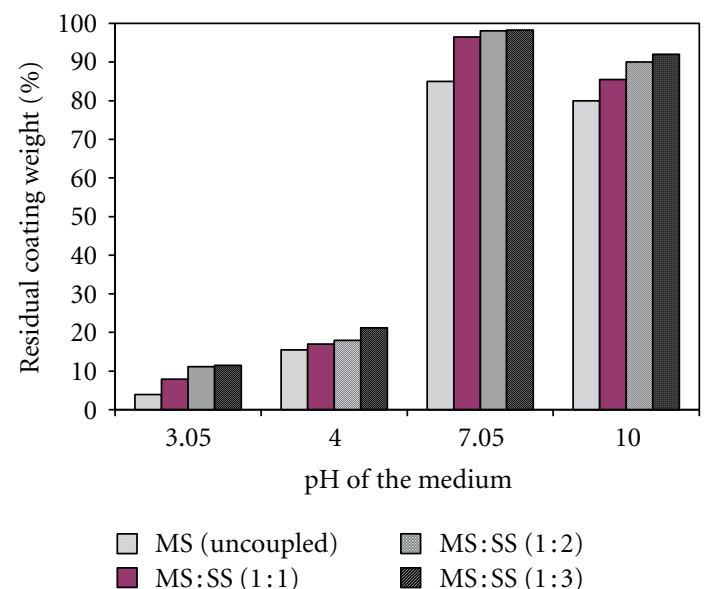

(a)

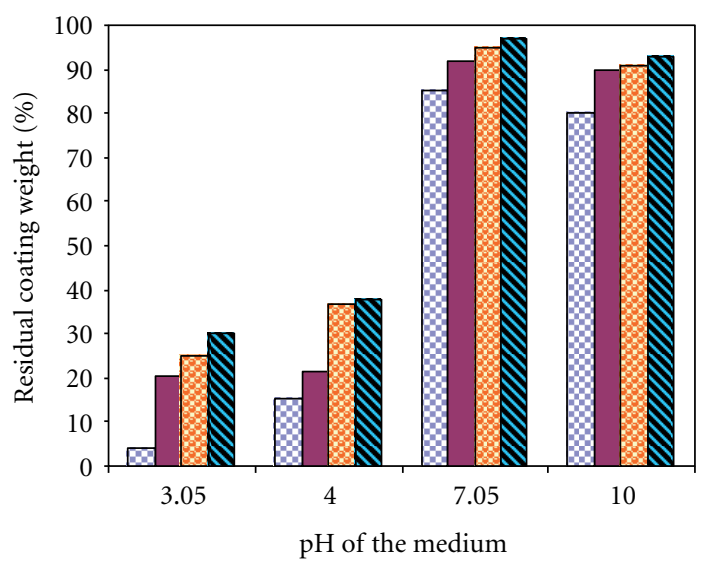

$\begin{array}{ll}\square \text { MS (uncoupled) } & \text { 圆 MS:BR }(1: 2) \\ \square \text { MS:BR }(1: 1) & \mathbf{N} \text { MS:BR }(1: 3)\end{array}$

(c)

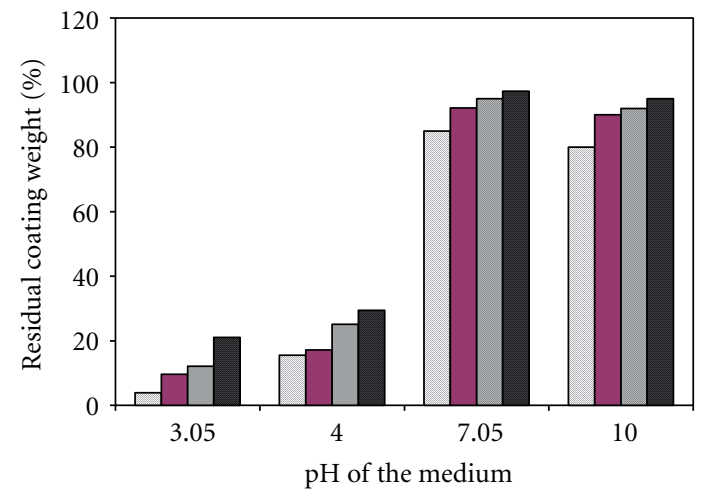

$\begin{array}{ll}\square \text { MS (uncoupled) } & \square \mathrm{MS}: \mathrm{Ni}(1: 2) \\ \square \mathrm{MS}: \mathrm{Ni}(1: 1) & \quad \mathrm{MS}: \mathrm{Ni}(1: 3)\end{array}$

(b)

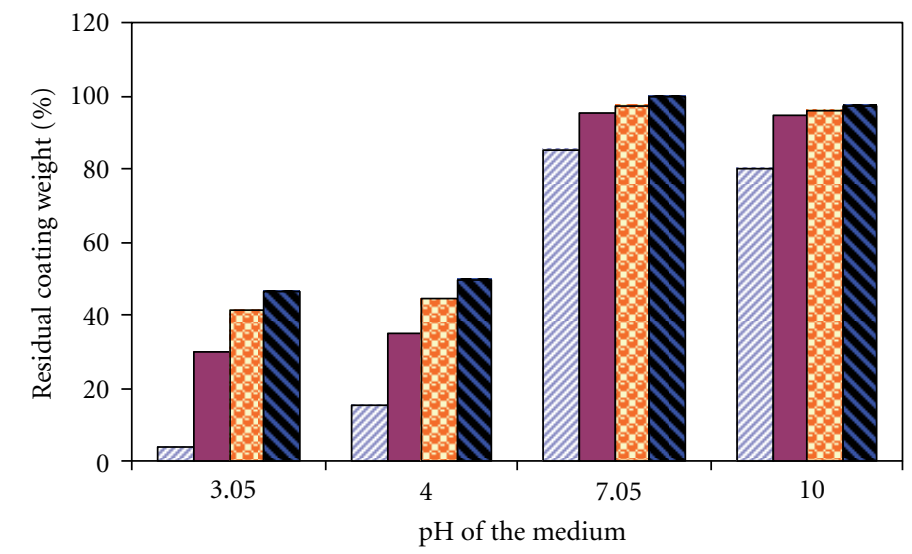

$\square S$ (uncoupled) $\quad$ MS: $\mathrm{Cu}(1: 2)$
$\mathrm{MS}: \mathrm{Cu}(1: 1)$

(d)

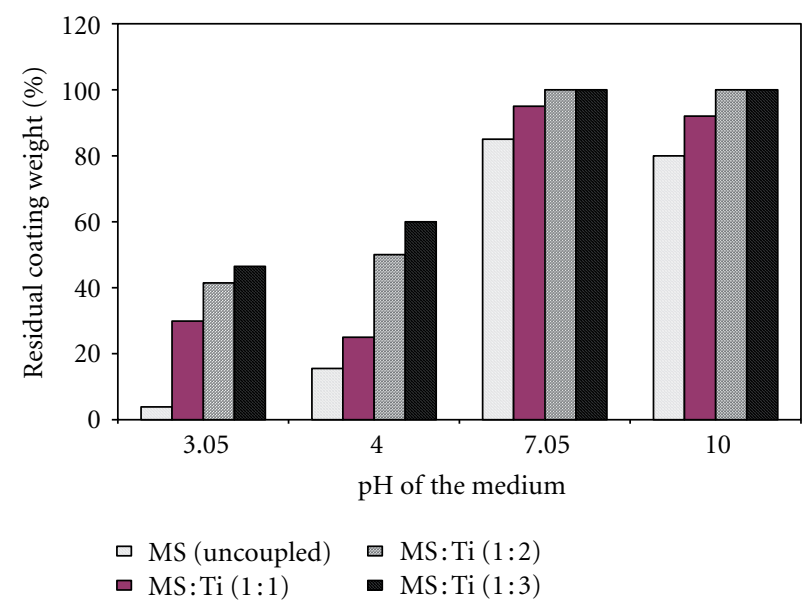

(e)

Figure 2: Chemical stability of phosphate coatings obtained under uncoupled and galvanically coupled conditions: (a)mild steel coupled with stainless steel (area ratio of MS to SS-1:1,1:2, and 1:3); (b) mild steel coupled with nickel (area ratio of MS to Ni-1:1,1:2, and $1: 3$ ); (c) mild steel coupled with brass (area ratio of MS to BR-1:1,1:2, and $1: 3$ ); (d) mild steel coupled with copper (area ratio of MS to Cu-1:1,1:2, and $1: 3$ ); (e) mild steel coupled with titanium (area ratio of MS to Ti-1:1,1:2, and $1: 3$ ). 


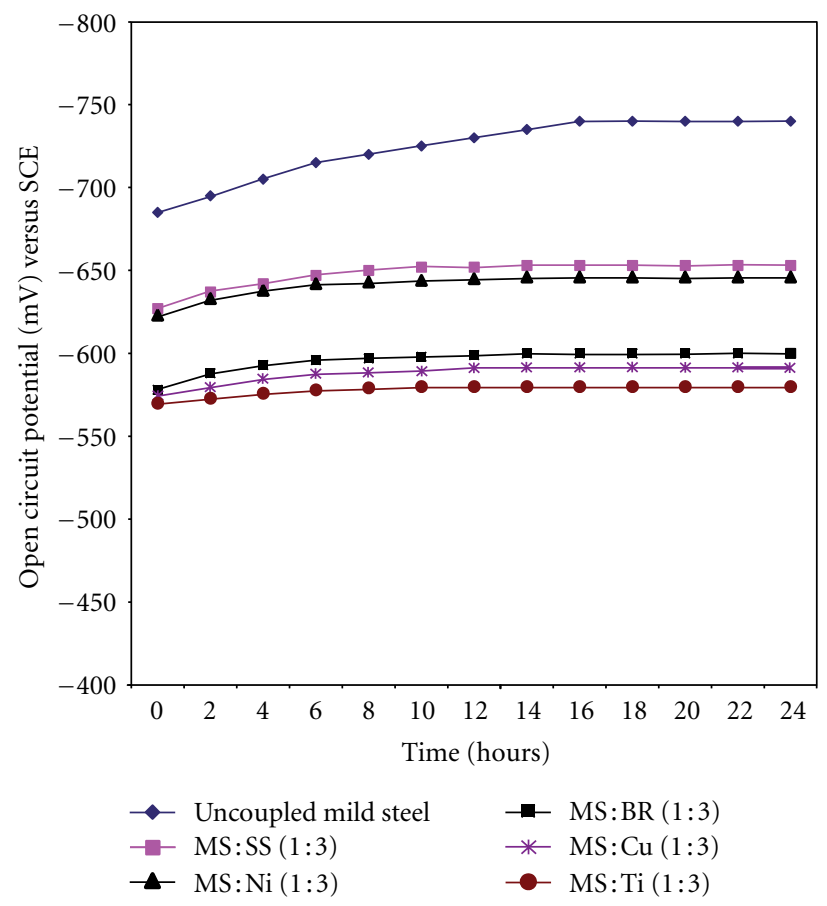

FIGURE 3: OCP of panels phosphated using different galvanic couples in 3.5\% sodium chloride solution as a function of immersion time.

Hence, the observed trend, that is, the relatively lesser percentage loss in weight obtained in the case of substrates coated under galvanically coupled condition suggests that a phosphophyllite-rich coating is formed in all the cases. Similarly, the observed chemical stability of the phosphate coatings also leads to the same expectation, since phosphophyllite-rich coatings possess a high alkaline stability. The formation of phosphophyllite rich coating in phosphating under galvanically coupled condition is further supported by the amount of iron dissolved during phosphating.

The thermal and chemical stabilities of the coating studied indicated that the mild steel substrates coated by galvanic coupling technique showed better corrosion resistance than the one coated without coupling. Among the couples studied, the mild steel-titanium couple of area ratio $1: 3$ possess the best stability.

\subsection{Immersion Test in 3.5\% Sodium Chloride Solution.} Immersion in $3.5 \% \mathrm{NaCl}$ solution provides an insight into the behaviour of phosphated mild steel substrates under galvanically coupled and uncoupled conditions. The extent of corrosion is assessed visually after 12 hours of immersion. The loss in weight due to corrosion is measured after 24 hours of immersion.

Observations made after 12 hours reveal that the panels phosphated under galvanically coupled condition remain in good condition and showed no rust spot formation. The amount of rust spots on the panels coated under galvanically coupled condition is very little than the one under uncoupled condition. Panels coated under galvanically coupled condition are having more uniform coating and possess a good corrosion resistance property when compared to panels coated under uncoupled condition. This is reflected in the loss in weight due to corrosion measured after 24 hours (Table 2).

The open circuit potential (OCP) of phosphated mild steel panels in $3.5 \%$ sodium chloride solution was measured every one hour for a period of 24 hours (Figure 3 ). The OCP appears to be a function of phosphate coating weight and porosity of the coating. Higher coating weight and lower porosity signify an anodic side OCP. The OCP which is found to shift to more negative values with increase in immersion though a saturation level in potential is reached after few hours of immersion. Among the panels coated using different galvanic couples, panels coated using mild steel-titanium couple with area ratio $(1: 3)$ exhibit a higher anodic shift in potential.

The mechanism of phosphating under galvanically coupled condition also supports this view; that under such condition the entire surface is accessible for phosphate coating formation in contrast to the availability of only cathodic sites when coated under uncoupled condition [8].

The formation of uniform coating delays the onset of corrosion in the case of panels phosphated under galvanically coupled condition. The extent of corrosion protection offered by the phosphate coatings obtained by using different galvanic couples and different area ratios seems to be the function of coating weight obtained under such conditions.

Mild steel substrates phosphated under galvanically coupled condition exhibited a better corrosion protection following immersion in $3.5 \%$ sodium chloride solution at $27^{\circ} \mathrm{C}$ for 24 hours than those coated without coupling. This indicated that phosphate coatings formed under galvanically coupled condition are relatively more uniform than the one coated 
TABLE 2: Loss in weight due to corrosion obtained for panels phosphated under galvanically coupled and uncoupled conditions following immersion in $3.5 \% \mathrm{NaCl}$ solution for 24 hours.

\begin{tabular}{lc}
\hline System studied & Loss in weight $^{*}\left(\mathrm{~g} / \mathrm{m}^{2}\right.$ ) \\
\hline Uncoupled mild steel & 0.68 \\
Mild steel coupled with stainless steel (area ratio of MS to SS-1:1) & 0.57 \\
Mild steel coupled with stainless steel (area ratio of MS to SS-1:2) & 0.53 \\
Mild steel coupled with stainless steel (area ratio of MS to SS-1:3) & 0.50 \\
Mild steel coupled with nickel (area ratio of MS to Ni-1:1) & 0.45 \\
Mild steel coupled with nickel (area ratio of MS to Ni-1:2) & 0.40 \\
Mild steel coupled with nickel (area ratio of MS to Ni-1:3) & 0.36 \\
Mild steel coupled with brass (area ratio of MS to brass-1:1) & 0.28 \\
Mild steel coupled with brass (area ratio of MS to brass-1:2) & 0.25 \\
Mild steel coupled with brass (area ratio of MS to brass-1:3) & 0.20 \\
Mild steel coupled with copper (area ratio of MS to $\mathrm{Cu}-1: 1$ ) & 0.18 \\
Mild steel coupled with copper (area ratio of MS to $\mathrm{Cu}-1: 2$ ) & 0.15 \\
Mild steel coupled with copper (area ratio of MS to $\mathrm{Cu}-1: 3$ ) & 0.12 \\
Mild steel coupled with titanium (area ratio of MS to Ti-1:1) & 0.08 \\
Mild steel coupled with titanium (area ratio of MS to Ti-1:2) & 0.05 \\
Mild steel coupled with titanium (area ratio of MS to Ti-1:3) & 0.04 \\
\hline
\end{tabular}

${ }^{*}$ Average of five determinations.

TABLE 3: Loss in weight due to corrosion obtained for panels phosphated under galvanically coupled and uncoupled conditions evaluated by ARE salt droplet test.

\begin{tabular}{lc}
\hline System studied & Loss in weight $^{*}\left(\mathrm{~g} / \mathrm{m}^{2}\right.$ ) \\
\hline Uncoupled mild steel & 29.10 \\
Mild steel coupled with stainless steel (area ratio of MS to SS-1:1) & 27.24 \\
Mild steel coupled with stainless steel (area ratio of MS to SS-1:2) & 26.71 \\
Mild steel coupled with stainless steel (area ratio of MS to SS-1:3) & 16.18 \\
Mild steel coupled with nickel (area ratio of MS to Ni-1:1) & 25.55 \\
Mild steel coupled with nickel (area ratio of MS to Ni-1:2) & 24.00 \\
Mild steel coupled with nickel (area ratio of MS to Ni-1:3) & 23.25 \\
Mild steel coupled with brass (area ratio of MS to brass-1:1) & 29.25 \\
Mild steel coupled with brass (area ratio of MS to brass-1:2) & 18.00 \\
Mild steel coupled with brass (area ratio of MS to brass-1:3) & 17.65 \\
Mild steel coupled with copper (area ratio of MS to Cu-1:1) & 18.13 \\
Mild steel coupled with copper (area ratio of MS to Cu-1:2) & 17.50 \\
Mild steel coupled with copper (area ratio of MS to $\mathrm{Cu}-1: 3$ ) & 16.00 \\
Mild steel coupled with titanium (area ratio of MS to Ti-1:1) & 13.00 \\
Mild steel coupled with titanium (area ratio of MS to Ti-1:2) & 12.00 \\
Mild steel coupled with titanium (area ratio of MS to Ti-1:3) & 10.05
\end{tabular}

${ }^{*}$ Average of five determinations.

without coupling. The formation of uniform coating delayed the onset of corrosion in the case of substrates phosphated under galvanically coupled condition. The extent of corrosion protection offered by the phosphate coatings obtained by using different galvanic couples and different area ratios seems to be a function of coating weight obtained under such conditions.

3.4. ARE Salt Droplet Test. The phosphated panels (under coupled and uncoupled conditions) subjected to A.R.E. salt droplet test were observed visually for the extent of corrosion everyday. The weight loss due to corrosion obtained after 5 days exposure (Table 3) clearly reveals that it is less for panels phosphated under galvanically coupled condition.

Although no significant difference could be observed from visual appearance, as all of them are severely corroded, the loss in weight due to corrosion varies significantly. This observation is not surprising, as the conditions simulated in this test are a combination of both salt spray and humid conditions. The water sprayed on the panels will not dry easily, since it is placed in a highly humid environment. Even though the test is performed at room temperature $\left(27^{\circ} \mathrm{C}\right)$, the humidity set in chamber will be higher than $65 \%$, which is sufficient to condense water on the panel dissolving the salt 


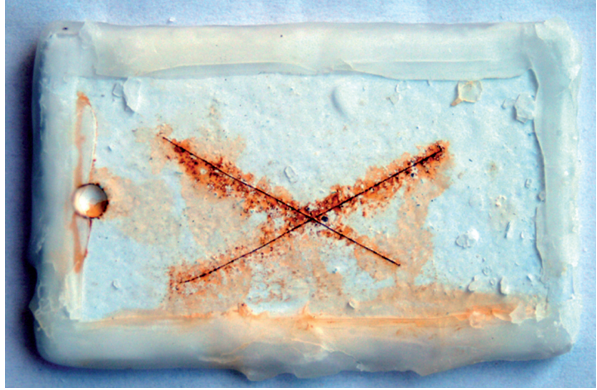

(a)

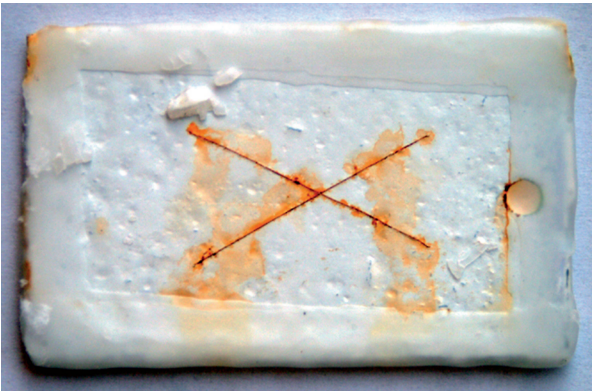

(c)

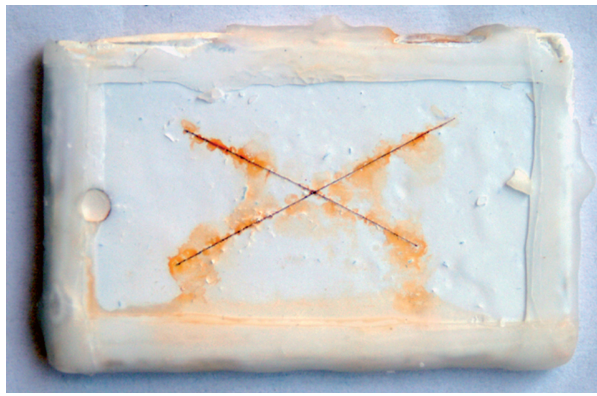

(e)

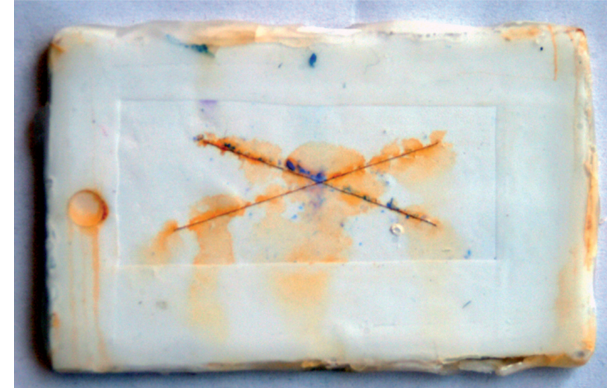

(b)

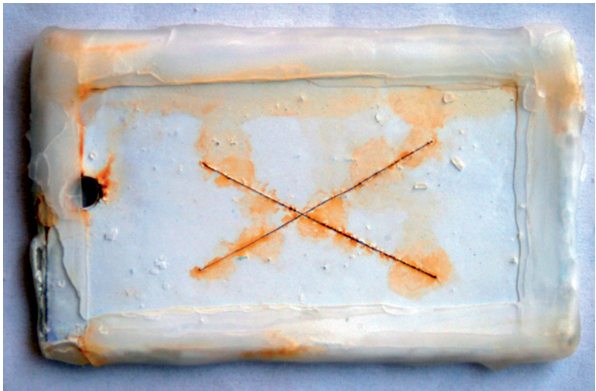

(d)

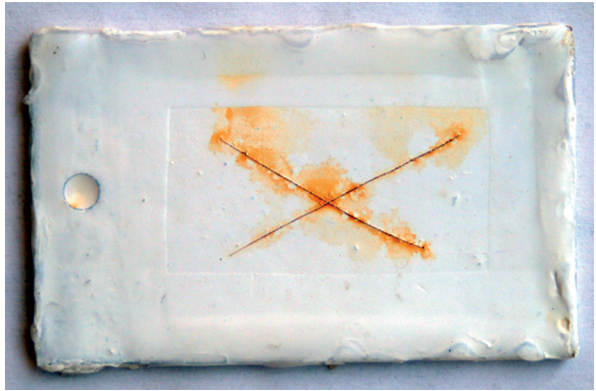

(f)

FIGURE 4: The corrosion behaviour of phosphated mild steel substrates under coupled and uncoupled conditions subsequently finished with a paint coating (DFT: $50 \mu \mathrm{m}$ ) after subjecting them to salt spray test for 96 hours. (a) Mild steel under uncoupled condition. (b) Mild steel coupled with stainless steel (area ratio 1:3). (c) Mild steel coupled with nickel (area ratio 1:3). (d) Mild steel coupled with brass (area ratio $1: 3$ ). (e) Mild steel coupled with copper (area ratio 1:3). (f) Mild steel coupled with titanium (area ratio $1: 3$ ).

particles, making regeneration of fresh electrolyte every time to cause severe corrosion. The weight loss due to corrosion is the least for the mild steel-titanium couple of area ratio $1: 3$ due to the higher coating weight of this couple. For phosphate coatings obtained using different galvanic couples, the loss in weight appears to be a function of the coating weight and porosity of the coating; higher the coating weight and lower the porosity of the coating, lesser the loss in weight due to corrosion.

3.5. Salt Spray Test. Salt spray test measures the ability of various types of coatings to withstand in a corrosivecum-humid atmosphere. As paint pretreatment coating, the phosphate coating is expected to improve the adhesion of the paint coating and prevents the spreading of underfilm corrosion. The ability to prevent underfilm corrosion is best measured by assessing the spreading of corrosion from the
X-scratch made on the phosphated and painted mild steel substrate [18].

The spreading of corrosion from the scribe is less in the case of panels coated under galvanically coupled condition than those coated under uncoupled condition after 96 hours of salt spray test (Figure 4). During salt spray test, chloride ions attack the base metal, forming iron (II) chloride followed by hydrolysis and rust formation at the anodic areas (exposed bare steel in the scribed region). The corresponding cathodic reaction is the reduction of oxygen to form hydroxide ions which dissolve the phosphate at the cathodic areas [17]. Energy dispersive X-ray analysis made on salt spray tested panels confirms that the exposed bare steel at the scribed region acts as the anode (based on the presence of chloride ions), and the phosphate coating present at the peripheral region acts as the cathode (based on the amount of phosphate left behind from leaching and also based on the presence of 
sodium ions) [17]. A similar mechanism takes place in all the cases of present study and follows the general mechanism as described above. In the salt spray test, as compared to the uncoupled mild steel substrate, the spreading of corrosion from the scribe is less for substrates phosphated under galvanically coupled conditions, following the high alkaline stabilities of the resultant phosphate coatings.

\section{Conclusion}

Salt spray testing and other methods of simulating corrosion performance have grown increasingly important as the call for quality has intensified. From the study, it is evident that galvanic coupling technique is capable of producing fine-grained, adherent coating with improved thermal and chemical stabilities, and corrosion resistance. The OCP determined during immersion in $3.5 \% \mathrm{NaCl}$ solution proved that the coating developed under galvanically coupled condition is uniform and less porous. The zinc phosphate coatings developed under galvanically coupled condition exhibited high corrosion resistance in $5 \% \mathrm{NaCl}$ solution as shown by salt spray test.

Comparing the electrochemical phosphating [18], adapting galvanic coupling methodology for producing zinc phosphate coatings with improved corrosion resistance using low temperature zinc phosphating processes is positively a costeffective approach.

\section{References}

[1] W. Rausch, The Phosphating of Metals, Finishing Publications, London, UK, 1990.

[2] D. B. Freeman, Phosphating and Metal Pretreatment-A Guide to Modern Processes and Practice, Industrial Press, New York, NY, USA, 1986.

[3] C. Rajagopal and K. I. Vasu, Conversion Coatings: A Reference for Phosphating, Chromating and Anodizing, Tata McGraw-Hill Publishing Company, New Delhi, India, 2000.

[4] T. S. N. Sankara Narayanan and M. Subbaiyan, "Overheating-its decisive role in phosphating," Metal Finishing, vol. 93, no. 1, pp. 30-31, 1995.

[5] T. S. N. S. Narayanan and M. Subbaiyan, "Effect of surfactants on the growth and crystal habit of zinc phosphate coating," Transactions of the Institute of Metal Finishing, vol. 71, no. 1, pp. 37-40, 1993.

[6] T. S. N. Sankara Narayanan, "Effect of surfactants on phosphate film epitaxy," Metal Finishing, vol. 94, no. 3, pp. 47-49, 1996.

[7] V. Burokas, A. Martušiene, and G. Bikulčius, "The influence of hexametaphosphate on formation of zinc phosphate coatings for deep drawing of steel tubes," Surface and Coatings Technology, vol. 102, no. 3, pp. 233-236, 1998.

[8] M. Arthanareeswari, T. S. N. Sankara Narayanan, P. Kamaraj, and M. Tamilselvi, "Polarization and impedance studies on zinc phosphate coating developed using galvanic coupling," Journal of Coatings Technology Research, vol. 9, no. 1, pp. 39-46, 2012.

[9] M. Arthanareeswari, T. S. N. Sankara Narayanan, P. Kamaraj, and M. Tamilselvi, "Influence of galvanic coupling on the formation of zinc phosphate coating," Indian Journal of Chemical Technology, vol. 17, no. 3, pp. 167-175, 2010.
[10] M. Arthanareeswari, K. Ravichandran, T. S. N. Sankara Narayanan, and S. Rajeswari, "Effect of cathode materials on the phosphatability and corrosion resistance of mild steel," Indian Surface Finishing, vol. 1, no. 1, pp. 80-88, 2004.

[11] M. Arthanareeswari, K. Ravichandran, T. S. N. Sankara Narayanan, P. Kamaraj, and S. Rajeswari, "Effect of cathode materials on the phosphatability and corrosion resistance of mild steel," Journal of Current Science, vol. 2, no. 2, pp. 153-160, 2002.

[12] K. Ravichandran, H. Sivanandh, S. Ganesh, T. Hariharasudan, and T. S. N. Sankara Narayanan, "Acceleration of the phosphating process-the utility of galvanic coupling," Metal Finishing, vol. 98, no. 9, pp. 48-54, 2000.

[13] T. S. N. Sankara Narayanan and M. Subbaiyan, "Effect of surfactants on the porosity and corrosion resistance of zincphosphated steel," Metal Finishing, vol. 91, no. 8, pp. 43-45, 1993.

[14] T. S. N. Sankara Narayanan and M. Subbaiyan, "Sodium diethyldithiocarbamate: an effective complexone for cold zinc phosphating," Transactions of the Institute of Metal Finishing, vol. 75, no. 12, pp. 81-83, 1992.

[15] T. S. N. Sankara Narayanan and M. Subbaiyan, "Influence of hexadecyl dithiocarbamate on phosphate surface chemical conversion coatings on mild steel," Surface and Coatings Technology, vol. 43-44, no. 1, pp. 543-553, 1990.

[16] T. S. N. Sankara Narayanan, "Comparison of coating weight and potential-time measurements in phosphating operations-a correlation study," Product Finishing, vol. 49, no. 2, pp. 31-33, 1996.

[17] S. Jegannathan, T. S. N. Sankara Narayanan, K. Ravichandran, and S. Rajeswari, "Performance of zinc phosphate coatings obtained by cathodic electrochemical treatment in accelerated corrosion tests," Electrochimica Acta, vol. 51, no. 2, pp. 247-256, 2005.

[18] S. Jegannathan, T. S. N. Sankara Narayanan, K. Ravichandran, and S. Rajeswari, "Evaluation of the corrosion resistance of phosphate coatings obtained by anodic electrochemical treatment," Progress in Organic Coatings, vol. 57, no. 4, pp. 392-399, 2006. 

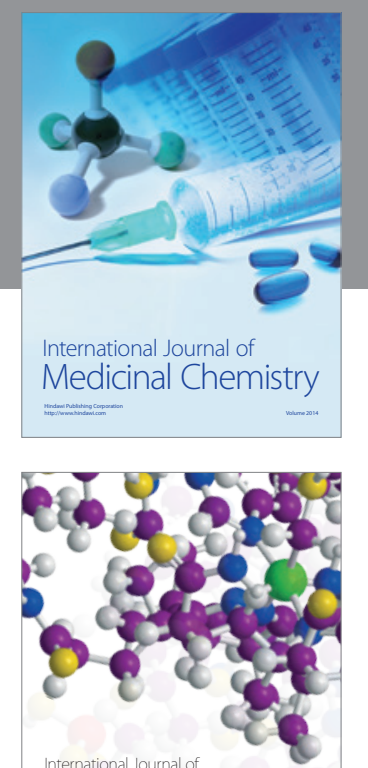

\section{Carbohydrate} Chemistry

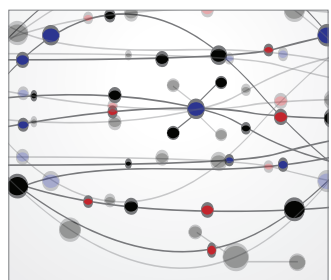

The Scientific World Journal
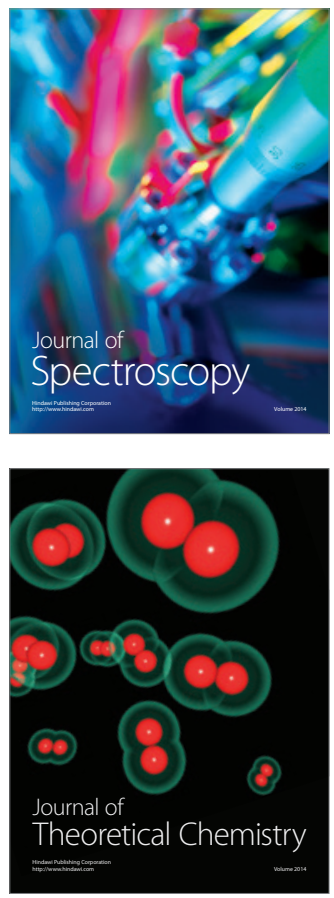
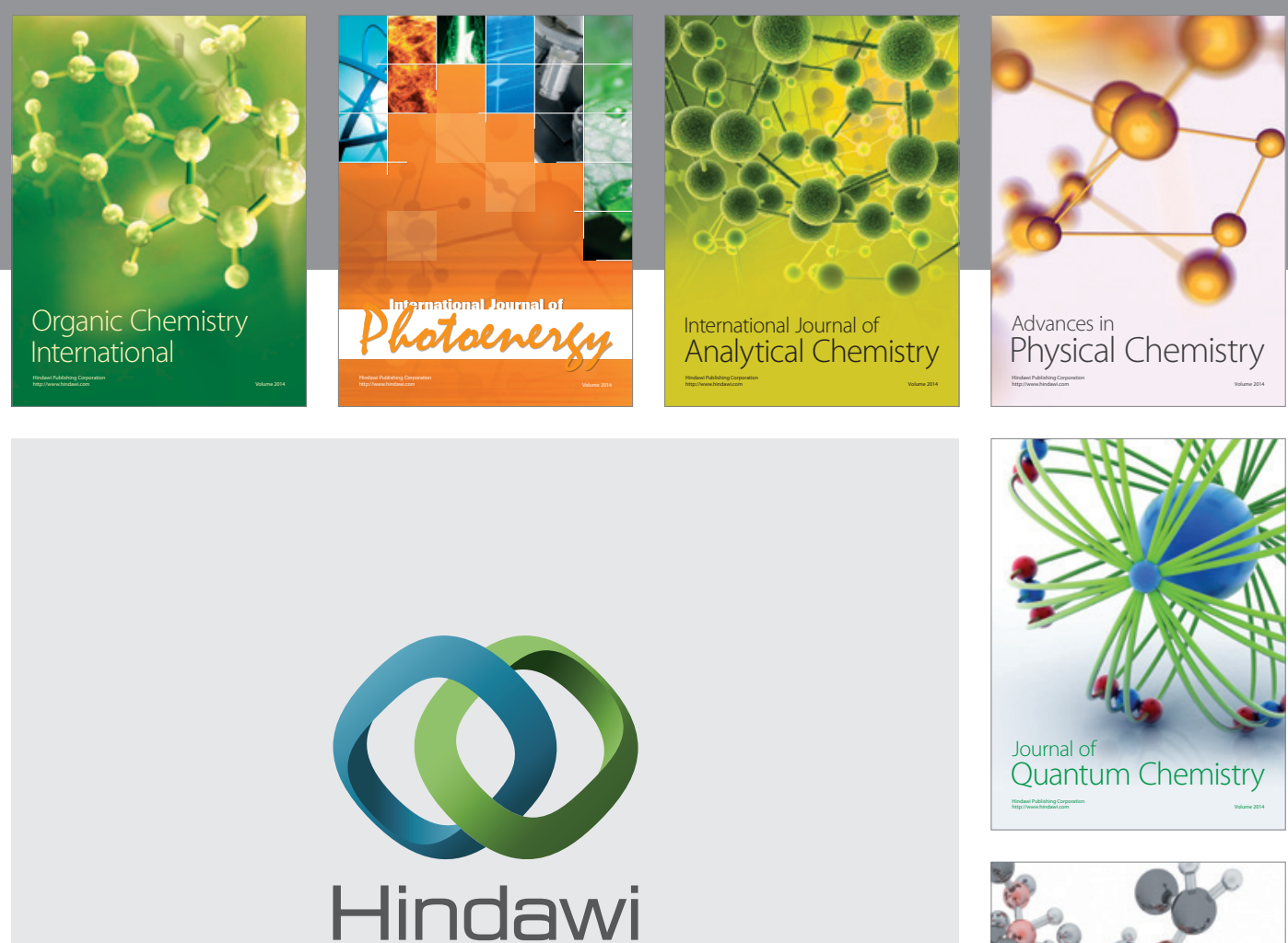

Submit your manuscripts at

http://www.hindawi.com

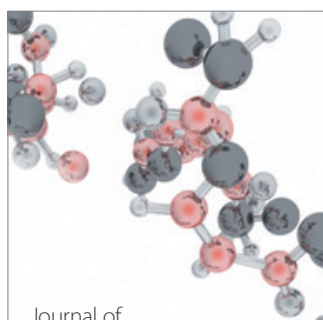

Analytical Methods

in Chemistry

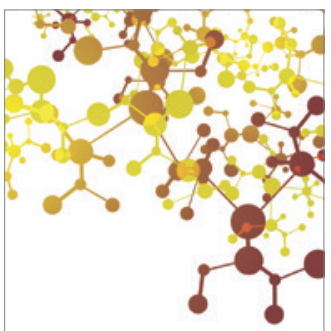

Journal of

Applied Chemistry

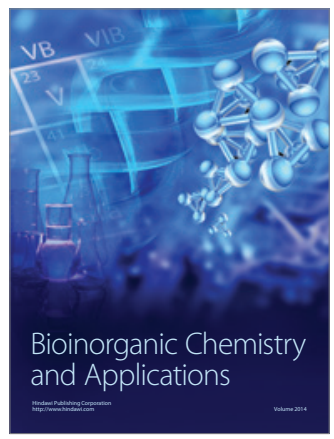

Inorganic Chemistry
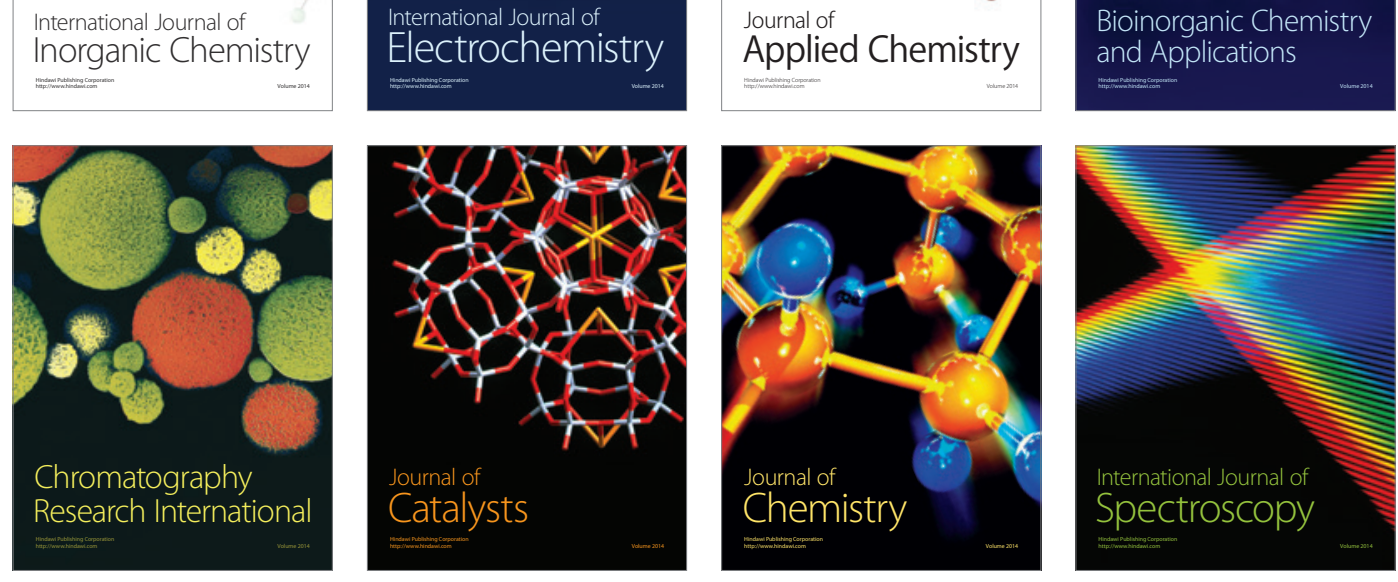